\title{
Analysis of Emotional Suppression and Marital Distress in the First Five Years of Marriage
}

\section{Tiara Syifa Fadhillah*, and Yudiana Ratnasari}

Department of Clinical Psychology, Faculty of Psychology, Universitas Indonesia, Depok Indonesia

\section{ORCID}

Tiara Syifa Fadhillah; https://orcid.org/0000-0003-3134-6795

\begin{abstract}
Emotional suppression is an emotion regulation strategy that is often used in Eastern or Asian cultures like in Indonesia. Emotional suppression can be related to various outcomes in marital relationships such as marital distress. This research explored the association between emotional suppression and marital distress in individuals during their first five years of marriage. 1770 married participants from various regions in Indonesia participated (mean marriage length $=23.49$ months). The research variables were measured using the Emotional Regulation Questionnaire (ERQ) and the Revised Dyadic Adjustment Scale (RDAS). Emotional suppression and marital distress were found to be negatively correlated. Differences in the norms in various situations across the culture seemed to influence the result. Inferential statistics were calculated to determine whether there was a significant difference in individual marital distress levels based on gender, the number of children, residential status, and changes in sexual activity during the Covid-19 pandemic.
\end{abstract}

Corresponding Author: Tiara Syifa Fadhillah; email: tiara.syifa@ui.ac.id

\section{Dates}

Published 28 January 2022

Publishing services provided by Knowledge E

(c) Tiara Syifa Fadhillah, and Yudiana Ratnasari. This article is distributed under the terms of the Creative Commons

Attribution License, which permits unrestricted use and redistribution provided that the original author and source are credited.

Selection and Peer-review under the responsibility of the ICoPsy Conference Committee.

\section{S OPEN ACCESS}

Keywords: marital distress, emotional suppression, early marriage, Covid-19 pandemic

\section{Introduction}

Marriage is one of the essential steps in the stages of individual development. Through marriage, individuals can meet the need for companionship, love, and support from their partners, as well as fulfilling their sexual needs and procreation [1]. In the process, couples will be faced with various tasks, such as negotiating about the fulfilment of roles and responsibilities, building their relationship as an individual and a couple, and learning how to maintain a developing relationship [2]. These tasks will be felt since the early days of marriage and will continue throughout the marriage. Frequently, conflicts and turmoil will arise in the process, which can cause distress to the couple [3].

According to Statistics Indonesia (BPS), in 2018, as many as 183,085 divorce cases in Indonesia were caused by continuous dispute and marriage quarrels. The number clearly shows that couples who are continually having unresolved conflicts decided 
to divorce. The accumulation of unresolved conflict can also lead to physical, psychological, emotional, mental, and spiritual consequences, known as marital distress [3]. One factor that can trigger marital distress is the accumulation of unresolved conflict stemming from avoidance [4]. This is done because most couples are apprehensive of their negative emotions and have difficulty managing them [1]. In the end, it is common for individuals to choose emotional suppressions in the hope that the negative emotions will go away on their own. Reducing or suppressing the expressions of emotions is a form of emotional regulation known as emotional suppression [5].

Individuals who suppress their emotions tend to experience much more negative and less positive emotional impulses [6]. Moreover, there is an increase in physiological reactions in sympathetic and cardiovascular activation [7] and an increase in blood pressure [8]. Emotional suppression was also found to reduce the psychological wellbeing and life satisfaction of individuals [6]. On the other hand, emotional suppression can result in communication disruption and stress to the interlocutor in an interpersonal relationship [9]. These effects lead to a lack of social support [5] and reciprocity from others [10]. Individuals will then feel an increase in stress within themselves and their relationship [1], so they might feel that their relationship is deteriorating [10]. [6] Found that emotional suppression negatively correlates with relationship satisfaction level and leads to more conflict in romantic relationships. Similar findings were also found in the study by [11], that emotional suppression was found to impair the quality of one's marriage during the early stages of marital transition. Emotional suppression can reduce intimacy and cause individuals to judge their relationship more negatively [9], [12], [6].

From some of the explanations outlined above, the researcher aims to know the relationship between emotional suppression with marital distress on individuals in their first five years of marriage. Previous research, such as that done by [6], found that emotional suppression can reduce the level of satisfaction in relationships. However, different results from emotional suppressions were found in participants with easter cultural backgrounds [8], [13]. The researcher, thus, wants to discover the effect of emotional suppressions on marital relations in Indonesia, as a country that belongs to the eastern tradition.

Alongside emotional suppressions, the research estimates that the current Covid-19 pandemic might have influenced the level of marital distress. The negative impacts of the pandemic, such as layoffs, economic difficulties, work stress, pandemic-induced uncertainty, and anxiety about health conditions [14], might act as additional stressors for individuals and couples. These stressors are associated with more significant emotional 
distress and can make it difficult for individuals or couples to behave constructivelywhich might lead to an increase in marital conflict and marital distress [14].

The Covid-19 pandemic has forced individuals to carry out their various activities from home. The social distancing policies and movement limitation can gradually blur the line between family and work roles, which pose particular difficulties for individuals. This disruption might lead to conflicts within these roles, disruption in family and professional affairs, and emotional tension [15]. The use of less effective emotional regulation, such as emotional suppression, can increase negative emotions and reduce individual wellbeing during the pandemic. Individuals might feel overwhelmed by the various stresses they experience, which can negatively affect their marital relationship, alongside additional external stressors and aggravating marital distress [16]. This situation also can make individuals or couples with poor adjustment and high conflict in their relationship will experience a slight decrease in relationship satisfaction which then suppressed the functioning of the relationship they have [17]. Therefore, research on emotional suppression and marital distress becomes relevant to be carried out on individuals who are in the first five years of marriage, given that the early period of marriage represents a transitional period in which dramatic changes and marital conflict are most intense and frequent [2].

\section{Literature Review}

Marital Distress defined as a multifaceted phenomenon in which individuals may experience dissatisfaction on certain dimensions of their marriage (e.g., sex, finances, communication) but not with other dimensions. This can be seen through disagreement and pressure on several dimensions of marriage including important issues in marriage (consensus), relationship satisfaction, the level of closeness of relationship and activities carried out with partner (cohesion), and affectional expression. Factors that can affect marital distress are the negative communication [4], parenting conflicts, quality time, conventionalism, conflict resolution style, number of children, residential status [18], changes in sexual activity [19]. One type of negative communication is avoidance which is related to stonewalling and characterized by a low level of emotional expression which is similar to what is known as emotional suppression.

Emotional Suppression defined as a form of emotion regulation that aims to inhibit the expressive behavior of the emotions felt. Emotional suppression is one way to suppress the emotional response that has been present and felt as an individual effort 
to reduce positive and negative emotional experiences [5]. Factors that can affect emotional suppression include gender [5], personality, and culture [8].

\section{Method}

The research design is cross-sectional, non-experimental because there is no manipulation of the variables studied, and the data collection is only done once. 1170 participants data, consisting of 871 women and 299 men were processed. Other data were not used due to incomplete submission of the form and ineligibility of some participants in meeting the research qualification. The marriage age of participants ranged from 0 months to 60 months ( $M=23.49$ months), with $0-2$ children. Additionally, most of the participants had previously been in a dating relationship before marriage (80.2\%). The Revised Dyadic Adjustment Scale (RDAS) by Busby, Christensen, Crane, and Larson (1995) with 14 items and the Emotional Regulation Questionnaire (ERQ) by [5] with 4 items were used to measure the level of marital distress and emotional suppressions. The measuring instruments were adapted by translating them from English into Indonesian. The data collection is done by distributing online questionnaires using Google Form and shared through various media social. A simple regression statistical analysis between emotional suppression and marital distress in individuals who were in the first five years of marriage was conducted using SPSS ver. 23. Analysis of t-test and ANOVA was also conducted on the research variables with participant demographic data to get a clearer picture of the participant's condition.

\section{Result and Discussion}

The analysis showed that there is a significant relationship between the two variables $(F(1,1168)=12,377, p<0.01)$ with an $R^{2}$ of 0.010 . Table 1 shows the results of the analysis of the relationship between marital distress and emotional suppression. These results indicate that the research hypothesis, namely emotional suppression has a significant relationship with marital distress in individuals who are in the first five years of marriage, can be accepted. The results of the analysis show that $1 \%$ of the variance in marital distress can be predicted by emotional suppression.

Table 1: Analysis Result on the Relationship between Emotional Suppression and Marital Distress

Analysis of t-test and ANOVA using SPSS ver. 23 was conducted on the emotional suppression and marital distress variables based on gender, the number of children, 
TABLE 1: Analysis Result on the Relationship between Emotional Suppression and Marital Distress

Research Variables
Emotional Suppression

\begin{tabular}{|l|l|l|l|}
\hline \multicolumn{4}{c|}{ Marital Distress } \\
\hline $\mathrm{R}$ & $\mathrm{R}^{2}$ & $\mathrm{~F}$ & $p$ \\
\hline-0.102 & 0.010 & 12.377 & 0.000 \\
\hline
\end{tabular}

TABLE 2: The Difference on the RDAS Score based on Gender and Sexual Activity.

\begin{tabular}{l|l|l|l|l} 
& N & Mean & t & Sig. \\
$\begin{array}{l}\text { Gender } \\
\text { Female }\end{array}$ & 871 & 49,61 & $-2,02$ & 0,044 \\
\hline $\begin{array}{l}\text { Male } \\
\text { Sexual Activity }\end{array}$ & 299 & 50,82 & & \\
$\begin{array}{l}\text { Affected } \\
\text { Not Affected }\end{array}$ & 236 & 46,95 & $-5,09$ & 0,000 \\
\hline
\end{tabular}

sexual activity, and residence status. Through the analysis, the significance of variable differences between the group of participants can be evaluated [20]. The numerical scores compared are the total RDAS and ERQ scores, while the cohort refers to the division of the group from various demographic data.

T-test results showed that there were significant differences in the marital distress level of female and male participants $t(1168)=-2,02, p<0,05$. Women show lower levels of marital stability and satisfaction, thus indicating higher marital distress when compared to men. Additionally, there was a significant difference in participants' marital distress based on changes in sexual activity during the Covid-19 pandemic $t(1168)=-$ $5,09, p<0,001$ (Table 2). Participants who reported that the pandemic affects their sexual activities with their partner had lower levels of marital stability and satisfaction, thus indicating higher distress compared to participants who reported that sexual activity with their partner was not affected during the COVID-19 pandemic.

TABLE 3: The Difference in the RDAS Score based on the Number of Children and Residential Status

\begin{tabular}{|c|c|c|c|c|}
\hline & $\mathbf{N}$ & Mean & SD & Sig. \\
\hline \multicolumn{5}{|c|}{ Number of Children } \\
\hline 0 & 540 & 50,73 & 8,41 & 0,006 \\
\hline 1 & 530 & 49,46 & 9,24 & \\
\hline 2 & 100 & 49,92 & 9,86 & \\
\hline \multicolumn{5}{|l|}{ Residential Status } \\
\hline With Partner & 679 & 50,44 & 8,46 & 0,001 \\
\hline $\begin{array}{l}\text { With Partner and } \\
\text { Parents }\end{array}$ & 345 & 49,96 & 9,58 & \\
\hline Apart due to Work & 146 & 47,44 & 9,29 & \\
\hline
\end{tabular}


The ANOVA analysis found a significant difference in the level of marital distress among groups based on the number of children $(F(2,1167)=5,11, p<0,05)$. Marital stability and satisfaction were higher in the participants in the group without children ( $M=50.73$, $S D=8.41)$ than in the group with one child $(M=49.46, S D=9.24))$ and groups with two children ( $M=49.92, S D=9.86$ ) (Table 3). Therefore, the higher the number of children an individual has, the lower the level of marital stability and satisfaction. In other words, the higher the level of marital distress they have. There is also a significant difference in the level of marital distress in the category based on residential status $(F(2,1167)=$ $6,81, p<0,05)$. Table 3 concludes that individuals who live with their partners have lower levels of marital distress than other groups.

Marital distress is a situation whereby individuals experience dissatisfaction in their marriage, characterized by emotional stress, conflict, and other difficulties experienced by individuals and their partners. One of the factors that can affect marital distress is emotional suppression, in which individuals tend to suppress and not express their emotions. This study found a significant relationship between emotional suppression and marital distress. The two variables are negatively correlated, which indicates that the higher the emotional suppression carried out by individuals in a marriage, the lower the level of marital stability and satisfaction, which eventually indicates a high level of marital distress. These findings are in line with the research conducted by [11], which found that the use of emotional suppression can damage marital relationships and reduce the quality of relationships during the early stages of marriage.

Emotional suppression shows that individuals withdraw from interactions that elicit certain emotions to avoid conflict. The withdrawal can reduce the level of intimacy, which then affects the marital relationship and create pressure for individuals. This shows that negative communication styles such as avoidance which are similar to suppression can actually affect relationships and marital distress in marriage. Although the results of the study show a significant correlation between emotional suppression and marital distress, the effect of emotional suppression tends to be small. It is assumed that there are other variables that act as a mediator on the relations between emotional suppression and marital distress. Thus, future research through mediation analysis should be carried out.

On the other hand, the results of this study are different from the researcher's assumptions and the results of the research conducted by [13]. [13] Found a more positive influence on people with cultural backgrounds from Eastern cultures or Asian countries. Considering that this research was conducted in Indonesia, which has characteristics adherent to Eastern culture, it was estimated that there would be a more positive relationship between emotional suppression and marital distress. Such a condition may 
occur because there is a difference in the norms of emotional expressions in various situations across cultures in Indonesia. One of them can be caused by display rules as sociocultural standards that regulate emotional states with when, where, and how emotions are expressed [21] in a different culture. Furthermore, emotional expression is also studied in relation to the cultural value of the subject's living environment. Therefore, it is possible for individuals to remain open with their families but not when they are outside because they are influenced by cultural factors adopted.

This study also found that there were differences in the level of marital distress in several groups of participants based on gender, changes in sexual activity, number of children, and residential status. The study found that women tend to feel more depressed and experience increased stress than men because they are overwhelmed with their responsibilities and roles to take care of their families and work [22]. These conditions can then affect the level of individual marital distress during the Covid-19 pandemic. This explanation is evident in the results of research which shows that the level of stability and marital satisfaction in female participants is lower than that of male participants.

As many as $20 \%$ ( $\mathrm{N}=233$ ) of study participants admitted that their sexual activity was affected during the pandemic. The results showed that individuals who reported that their sexual activity with their partner was affected during the pandemic had higher levels of marital distress than those who were not. The results are in line with [23] on the effect of the pandemic on individual sexual activity, which resulted in the finding that there was a decrease in the frequency and change in the type of sexual activity. [19] Changes in sexual activity during the pandemic with the married couple were caused by the experience of worries, lack of privacy, and stress. The fear of Covid-19 spread between couples who engaged in sexual activities was the cause of concern. There are also concerns for the safety of their children. The isolation and lockdown cause individuals to spend almost all of their time with children and families, resulting in a lack of privacy which in turn reduced intimacy with partners [24], [19].

Most of the current study participants do not have or have had one child. The biggest problem for married couples in parenting is having children that had a negative impact on marital satisfaction [1]. The sentiment is reinforced with married couples reporting that they feel more dissatisfied and feel pressured in marriage after having children [1]. In line with this explanation, the results of the study show that the more children an individual has, the lower the level of marital stability and satisfaction. In other words, the higher the number of children, the higher the individual marital distress. Some factors that might play a role in creating this condition include the couple's lack of involvement 
in child care, and the amount of attention focused on marriage is not balanced with the attention given to their children. Therefore, a higher number of children may increase the level of stress felt by married couples. This is especially the case during the pandemic when the presence of children at home due to isolation and quarantine can create tension and increase the need for child care [22].

The residential status for couples was also found to have an influence on the individual's marital distress. Couples sometimes do long-distance marriages due to work that makes one partner live apart from each other. Being separated from a partner certainly makes a change in communication patterns and can be one of the causes of disturbances [18] or marital failure [25]. The study found that individuals who live separately from their partners tend to have a higher level of marital distress than individuals who live with their partners. The inability of one partner to optimally perform their role and the many obstacles that exist make long-distance relationships can be complicated for many couples [26].

The study is limited due to the large difference between the number of male and female participants. Balancing the sample is necessary for future studies to support the analysis of research variables between sexes. It is also suggested that future research can conduct research in pairs to get a dyadic data, considering that the marriage involves two individuals who are interrelated. Both the husband and the wife can participate in the study, although they should fill out the questionnaire separately. In addition, as the majority of the population sample have had a relationship before marriage, further research can balance the number of participants with other backgrounds (such as ta'aruf and arranged marriages). Inclusion of participants with other backgrounds can be done so that the research sample can be more representative and the research results can describe the relationship between variables that may be different, and then can act as a comparison of the majority of the population in the study.

\section{Acknowledge, Funding \& Ethics Policies}

The author(s) received no financial support for the research, authorship, and/or publication of this article. All authors contributed to, reviewed, and commented on drafts of the manuscript. All authors read and approved the final manuscript. 


\section{References}

[1] Olson DH, DeFrain J, Skogrand L. Marriages and families: Intimacy, diversity, and strengths. $9^{\text {th }}$ ed. New York: McGraw-Hill Education; 2019.

[2] Bradbury TN, Weiss RL. The developmental course of marital dysfunction. Cambridge: Cambridge University Press; 2006.

[3] Anim MT. Psychosocial factors influencing marital distress in Ghanaian married couples. Research on Humanities and Social Sciences. 2013;3(1):161-171.

[4] Markman HJ, Rhoades GK, Stanley SM, Ragan EP, Whitton SW. The premarital communication roots of marital distress and divorce: The first five years of marriage. Journal of Family Psychology. 2010;24(3), 289-298. https://doi.org/10.1037/a0019481

[5] Gross JJ, John OP. Individual differences in two emotion regulation processes: Implications for affect, relationships, and well-being. Journal of Personality and Social Psychology. 2003;85(2):348-362. https://doi.org/10.1037/0022-3514.85.2.348

[6] Impett EA, Kogan A, English T, et al. Suppression sours sacrifice: Emotional and relational costs of suppressing emotions in romantic relationships. Personality and Social Psychology Bulletin. 2012;38(6):707-720. https://doi.org/10.1177/0146167212437249

[7] Gross JJ, Levenson RW. Hiding feelings: The acute effects of inhibiting negative and positive emotion. Journal of Abnormal Psychology. 1997;106(1):95-103. https://doi.org/10.1037/0021-843X.106.1.95

[8] Butler EA, Lee TL, Gross JJ. Does expressing your emotions raise or lower your blood pressure? The answer depends on cultural context. Journal of Cross-Cultural Psychology. 2009;40(3):510-517. https://doi.org/10.1177/0022022109332845

[9] Butler EA, Egloff B, WIhelm FH, Smith NC, Erickson EA, Gross JJ. The social consequences of expressive suppression. Emotion. 2003;3(1):48-67. https://doi.org/10.1037/1528-3542.3.1.48

[10] Righetti F, Balliet D, Visserman M, Hofmann W. Trust and the suppression of emotions during sacrifice in close relationships. Social Cognition. 2015;33(5):505519. https://doi.org/10.1521/soco.2015.33.5.505

[11] Velotti P, Balzarotti S, Tagliabue S, English T, Zavattini GC, Gross JJ. Emotional suppression in early marriage: Actor, partner, and similarity effects on marital quality. Journal of Social and Personal Relationships. 2016;33(3):277-302. https://doi.org/10.1177/0265407515574466

[12] Chervonsky E, Hunt C. Suppression and expression of emotion in social and interpersonal outcomes: A meta-analysis. Emotion. 2017;7(4):669-683. https://doi.org/10.1037/emo0000270 
[13] Le BM, Impett EA. When holding back helps: Suppressing negative emotions during sacrifice feels authentic and is beneficial for highly interdependent people. Psychological Science, 2013;24(9):1809-1815. https://doi.org/10.1177/0956797613475365

[14] Pietromonaco PR, Overall NC. Applying relationship science to evaluate how the COVID-19 pandemic may impact couples' relationships. American Psychologist. 76(3), 438-450. 2020. https://doi.org/10.1037/amp0000714

[15] Restubog SLD, Ocampo ACG, Wang L. Taking control amidst the chaos: Emotion regulation during the COVID-19 pandemic. Journal of Vocational Behavior. 2020;119:103440. https://doi.org/10.1016/j.jvb.2020.103440

[16] Maiti T, Singh S, Innamuri R, Hasija AD. Marital distress during COVID-19 pandemic and lockdown: A brief narrative. The International Journal of Indian Psychology. 2020;8(2):426-433.

[17] Williamson HC. Early effects of the COVID-19 pandemic on relationship satisfaction and attributions. Psychological Science. 2020. 095679762097268. https://doi.org/10.1177/0956797620972688

[18] Gravningen K, Mitchell KR, Wellings K, et al. Reported reasons for breakdown of marriage and cohabitation in Britain: Findings from the third National Survey of Sexual Attitudes and Lifestyles (Natsal-3). PLOS ONE. 2017;12(3):e0174129. https://doi.org/10.1371/journal.pone.0174129

[19] Panzeri M, Ferrucci R, Cozza A, Fontanesi L. Changes in sexuality and quality of couple relationship during the Covid-19 lockdown. Frontiers in Psychology. 2020;11:565823. https://doi.org/10.3389/fpsyg.2020.565823

[20] Gravetter FJ, Forzano L-AB. Research Methods for the Behavioral Sciences. Massachusets: Cengage Learning. 2018.

[21] Ekman P. Should we call it expression or communication? Innovation: The European Journal of Social Science Research. 1997;10(4):333-344. https://doi.org/10.1080/13511610.1997.9968538

[22] Kowal M, Coll-Martín T, Ikizer G, et al. Who is the most stressed during the Covid19 pandemic? Data from 26 countries and areas. Applied Psychology: Health and Well-Being. 2020;12(4):946-966. https://doi.org/10.1111/aphw.12234

[23] Lehmiller JJ, Garcia JR, Gesselman AN, Mark KP. Less sex, but more sexual diversity: Changes in sexual behavior during the COVID-19 coronavirus pandemic. Leisure Sciences. 2020;1-10. https://doi.org/10.1080/01490400.2020.1774016

[24] Arafat SMY, Alradie-Mohamed A, Kar SK, Sharma P, Kabir R. Does COVID-19 pandemic affect sexual behaviour? A cross-sectional, cross-national online survey. Psychiatry Research. 2020;289. https://doi.org/10.1016/j.psychres.2020.113050 
[25] Lavner JA, Karney BR, Bradbury TN. Does couples' communication predict marital satisfaction, or does marital satisfaction predict communication? Journal of Marriage and Family. 2016;78(3):680-694. https://doi.org/10.1111/jomf.12301

[26] Harsari RJT. A perspective of husband and wife roles in long-distance marriage. 5th ASEAN Conference on Psychology, Counselling, and Humanities (ACPCH 2019). 2020 January 22; Penang, Malaysia. https://doi.org/10.2991/assehr.k.200120.056 